\title{
'Fixing' the climate crisis: capital, states, and carbon offsetting in India
}

Gareth Bryant

Department of Political Economy, School of Social and Political Sciences, Faculty of Arts and Social Sciences, University of Sydney, NSW, 2006, Australia; e-mail: gareth.bryant@sydney.edu.au

\section{Siddhartha Dabhi}

Ecology, Environment and Sustainable Development at the Tata Institute of Social Sciences, Guwahati 781 001, India; e-mail: siddhartha.dabhi@gmail.com

\section{Steffen Böhm}

Essex Sustainability Institute, Essex Business School, University of Essex, Colchester CO4 3SQ, England; e-mail: steffen@essex.ac.uk Received 23 September 2013; in revised form 23 April 2014; published online 22 January 2014

\begin{abstract}
The paper analyzes dynamics of accumulation and displacement in the Clean Development Mechanism (CDM). It combines the theoretical work of David Harvey and James O'Connor with a case study of the Gujarat Fluorochemicals Limited HFC-23 destruction project in Gujarat, India. The framework is used to connect the factors driving opportunities for capital accumulation in the CDM market with the causes of social and ecological dislocation at the local project level. We argue that the CDM is a spatial fix to the ecological crisis of climate change which secures conditions of production for fossil fuel industries and promotes new sites of accumulation for other companies. The politicaleconomic 'fix' is dependent on 'fixing' a global sociospatial divide between developed and developing countries down to 'fixed' projects at the local level. This spatial fix facilitates a displacement of the costs of responding to the climate crisis from North to South.
\end{abstract}

Keywords: Clean Development Mechanism, carbon offset, spatial fix, CDM, climate crisis

\section{Introduction}

Critical researchers have analyzed the 'new carbon economy' according to political economic interests that underpin market-based mechanisms (Bailey and Wilson, 2009). Bumpus and Liverman (2008) and Matthews and Paterson (2005) explain the dominance of emissions trading and carbon offsetting schemes in international climate policy in terms of state support for capital accumulation. They argue that carbon markets provide opportunities for the accumulation of capital in the carbon trading industry and protect the profits of fossil fuel industries by allowing them to avoid costly emission reductions.

The socioecological outcomes of protecting and promoting capital accumulation in this way have also been the subject of extensive criticism. Lohmann (2010, page 238) identifies a disjuncture between carbon offsets as units of "climate action" and the urgent need to create a historical pathway away from fossil fuel dependence. Bachram (2004, page 10) concludes that the expropriation of Southern nature through offsetting markets constitutes "carbon colonialism" at the expense of the people and ecosystems affected by offsetting projects. Case studies collected by Lohmann (2006), Böhm and Dabhi (2009), and Ghosh and Sahu (2011) show that offset projects have repeatedly dispossessed communities from their land and polluted local environments. The result has been the entrenchment or exacerbation 
of existing class (Vlachou and Konstantinidis, 2010), race, gender (Bond, 2007), regional (Corbera and Brown, 2010), and global (Böhm et al, 2012) inequalities, which would need to be confronted in any effective and just response to climate change.

This paper contributes to the growing body of literature on the political economy of carbon markets by analyzing the most extensive international carbon offsetting instrument: the United Nations (UN) Clean Development Mechanism (CDM). Together with Emissions Trading and Joint Implementation, the CDM is one of the three 'flexibility mechanisms' in the Kyoto Protocol. It promotes the development of carbon pollution reduction projects such as hydroelectric dams and industrial gas destruction factories in developing countries. The official purpose of the instrument is twofold: to produce carbon credits known as Certified Emission Reductions (CERs) for developed countries to use in accordance with their emission reduction requirements under the Kyoto Protocol and to promote 'sustainable development' in the South (UNFCCC, 1997, page 11). This paper responds to the empirical and theoretical agenda suggested by Bumpus and Liverman (2008) in their "accumulation by decarbonization" thesis by developing a theoretical framework based on the work of O'Connor (1998) and Harvey (1982). The framework is used to explain the socioecological and political economic outcomes generated in one industrial gas destruction CDM project in western India.

First, Bumpus and Liverman (2008, pages 148-149) suggest there is a need for "further theoretical work on the commodification of carbon [and] the spatial relations of emissions trading." They put forward Harvey's 'spatial fix' as one possible theoretical understanding of the CDM because "in organizing costly emission reductions through a geographic expansion of markets ... [offsetting] ... parallels other ways that capital avoids economic crises" (Bumpus and Liverman, 2008, page 134), but the argument is then not developed further. Bond (2012) also makes a limited conceptual reference to carbon offsetting as a spatial fix to suggest parallels between carbon offsetting and the history of waste displacement from North to South. In 1992, former World Bank Chief Economist Larry Summers exemplified this history in a leaked memo that stated Africa was "vastly under-polluted"-an economic logic that is replicated in the search for 'least cost' emissions reductions in the CDM. This paper deepens existing theoretical analyses of the CDM that emphasize dynamics of accumulation and displacement by combining Harvey's notion of the 'spatial fix' and O'Connor's development of Marx's conception of the 'conditions of production'.

Second, Bumpus and Liverman (2008, page 148) identify the need for "detailed empirical studies of carbon reductions in particular places and through different networks and value chains." Existing empirical studies have focused on the role of different combinations of local communities, project developers, associated carbon trading industries, national states, and international agreements in shaping the outcomes of individual CDM projects (Boyd, 2009; Bumpus, 2011; Corbera and Brown, 2010; Lansing, 2010; Yamane, 2009). However, they have not analyzed how CDM projects relate to global carbon markets by considering their particular links with fossil fuel industries in the North through the exchange of CERs. This paper addresses this gap with a detailed case study of the Gujarat Fluorochemicals Limited (GFL) HFC-23 destruction project in Gujarat, India, which connects the factors driving opportunities for capital accumulation in the CDM market with the causes of social and ecological dislocation at the project level.

The structure of the paper proceeds as follows. The next section is a theoretical discussion on how Harvey's concept of the spatial fix can be used to understand the development and operation of the CDM by drawing on O'Connor's understanding of ecological crisis and the conditions of production. The GFL case-study section documents the commodity networks engendered by the project involving direct project participants, financial actors in secondary markets, states, and polluting companies as well as its negative impacts on the 
local environment and the health and livelihoods of local communities. The paper concludes by bringing together the empirical data and theoretical framework. We argue that the CDM is a spatial fix to the ecological crisis of climate change, which secures production conditions for the fossil fuel industry and promotes new sites for accumulation for other companies by displacing the costs of responding to the climate crisis from North to South. It also considers recent developments in the CDM market including the collapse of offset prices and new restrictions on the HFC-23 project type through the contradictions of the CDM as accumulation strategy (Smith, 2006).

\section{Theorizing the CDM}

\section{Ecological crisis, conditions of production, and the spatial fix}

Harvey's (1982, page 424) 'third cut' at crisis theory identifies the spatial fix as a critical strategy used by states and capital to temporarily overcome crises of overaccumulation. These crises develop when the internal contradictions of capitalism undermine opportunities for the profitable realization of surplus value. Spatial fixes rely on "geographical expansion, spatial reorganization and uneven geographical development" to produce spaces and scales that restore conditions for capital accumulation and defer the devaluation of capital (Harvey, 1995, page 2). However, spatial fixes often amount to a displacement of crisis due to both the immediate social dislocation caused by the initial reconfiguration and the inevitable reproduction of the same crisis tendencies (Harvey, 2003, page 117).

O'Connor (1998) extends the Marxist theory of overaccumulation crisis arising from the 'first contradiction' between capital and labor to ecological concerns. The formulation begins with the contention that capitalism has a tendency to materially degrade or 'underproduce' its natural (and spatial and personal) conditions of production which are not wholly produced by capital and therefore secured by the state (O'Connor, 1998, pages 164-167). This 'second contradiction' between capital and nature creates the possibility of the formation of ecological crises. Such crises manifest as economic costs to capital and capitalist states if the use values of nature are sufficiently impaired and/or social contestation over degradation of nature is sufficiently strong to create a barrier to accumulation (O'Connor, 1998, page 242; Rosewarne, 1997, page 112).

Like Harvey, O'Connor (1998, pages 167-168) identifies a number of strategies that states and capital have developed in order to temporarily resolve ecological crises including technological fixes and environmental regulation. Of particular interest to the analysis of the CDM as a spatial fix is O'Connor's (1998, page 167) contention that these strategies attempt to "restructure production conditions with the aim of raising profits", which implies a spatial element to crisis-induced changes in social relations with nature (emphasis added). Harvey's spatial fix could therefore provide a useful way of addressing O'Connor's underdevelopment of the relationship between nature and space as conditions of production.

However, O'Connor's theory has been criticized for having a dualist ontological basis that posits a separation between capital and nature. Indeed, Harvey (1996, pages 146-147) has placed O'Connor's work within a Marxist reversion to "ecoscarcity and natural limits" analysis which treats nature as an "axiomatic limiting condition of human existence." Harvey's (1982, chapters 12 and 13) emphasis on the reconfiguration of built environments in spatial fixes demonstrates that the production of nature is central to his understanding of economic crisis. Conversely, O'Connor's thesis is organized in terms of an "epic" clash between the separate economic and ecological spheres of capitalism and the environment (Castree, 2002, pages 124-125).

Despite the dualistic presentation, O'Connor's (1998, chapter 7) development of Marx's conception of the conditions of production as productive forces and social relations of production reveals an ontology of nature that is substantively compatible with Harvey's. 
As social relations, natural conditions are "produced and reproduced (or made accessible) within definite property, legal and social relationships" (O’Connor, 1998, page 148). Through this lens, the widespread introduction of fossil fuel combustion as a productive force in 19th-century industry was necessitated by capitalist social relations impelling labor productivity improvements and the creation of a flexible and disposable workforce (Huber, 2009). The resulting (second) contradiction between capital and the climate system, which like fossil fuel is also a condition of production, is therefore a product of a historically specific manifestation of the (first) contradiction where capital has replaced labor power with greenhouse gas emissions. In this way, ecological crises, such as climate change, are a "specifically capitalist scarcity ... whereby capital creates its own barrier (or limit?)" (O’Connor, 1998, page 159).

The question mark on the nature of challenge posed by ecological crisis to capital reflects uncertainty over whether it will result in barriers to accumulation or opportunities for profit. The answer is always mediated by political contestation over the social regulation of nature between capital, social movements, and the state (O'Connor, 1998, page 165). O'Connor's focus on the concrete political economic factors shaping the course of ecological crises provides the framework needed to apply the concept of spatial fix, which Harvey originally developed in relation to overaccumulation crises, to climate politics and the CDM.

\section{The CDM as spatial 'fix'}

The CDM can be understood as a spatial fix to the ecological crisis of climate change by considering both meanings of 'fix' identified by Harvey. The first is the metaphorical meaning of 'a fix' as a temporary resolution, and the second is the material idea of spatial 'fixity' (Harvey, 2003, page 115). In the metaphorical sense the CDM is a spatial 'fix' for capital to avoid the potential costs of climate policy. The disruption of the climate system - a condition of production in the form of a carbon sink - will raise costs for many forms of capitalist production and cause social dislocation (Stern, 2007). In the short term, though, most potential costs to business from climate change come in responses to these material impacts in the form of social regulation of the climate. This is because stringent and enforced restrictions on greenhouse gas emissions could politically deprive fossil-fueldependent capital of the energy source that Malm (2013, page 51) describes as "the general lever for surplus-value production". The fix which secured continued access to fossil fuels and carbon sinks as conditions of production for Northern capital was the product of the institutionalization of international political contestation between states, capital, and social movements at UN climate negotiations.

At the time of the Kyoto climate conference in 1997 the political position of Northern corporations with varying economic interests in fossil fuels and climate policy was mixed. They ranged from outright opposition to mandatory action from the Global Climate Coalition representing fossil fuel interests, to calls for 'flexibility' from the International Climate Change Partnership representing mainly manufacturers, to support for green technology opportunities from the Business Council for Sustainable Energy (Levy and Egan, 1998, page 346). The demands of climate movements were similarly variegated. However, the larger environmental NGOs from both North and South were brought together under the umbrella of the Climate Action Network (CAN), which called for binding and domestic reductions of $20 \%$ by 2005 for developed countries and opposed emissions trading (Betsill, 2002, page 53). The Kyoto Protocol included elements of each of these positions. The 5\% overall emission reduction cap from 1990 levels by 2012 was binding but of a lower magnitude and slower timetable than demanded by CAN. The US government subsequently adopted the 'do nothing' approach exemplified by the Global Climate Coalition by not ratifying the agreement but not before 
securing the inclusion of the CDM as a 'flexibility mechanism' for achieving the Kyoto targets (Grubb et al, 1999, pages 102-103).

The CDM provides flexibility for capital by restructuring the geographical management of greenhouse gas emissions and carbon sinks. It builds on the general sociospatial divide between developed and developing countries at UN climate conferences-codified as Annex I and non-Annex I countries to the United Nations Framework Convention on Climate Change - to create an external space in the South where carbon sink capacity can be produced and an internal space in the North where carbon sink capacity can be consumed. Like spatial fixes to crises of overaccumulation that use external territories to overcome immediate social constraints, the CDM allows Northern capital to draw on abstract carbon sink capacity produced in developing countries to offset their continued use of material carbon sinks as conditions of production. Similarly, the fix also aims to support profit rates by protecting fossil fuel industries against costly emission reductions and promoting economic opportunities for a range of financial, green technology, and other industries involved in the production and trading of abstract carbon sinks as CERs.

The 'fixity' component of the spatial fix refers to tensions between the need to geographically 'fix' spatial configurations and physical infrastructure and the drag of this produced space and nature on the mobility of capital in future spatial fixes (Harvey, 2001, page 25; see also Brenner, 1998; Smith, 2008). The spatial fix for Northern capital is thus dependent on the differentiation of global space into 'fixed' internal and external spaces. This requirement for spatial fixity goes down to the local level of material and often largescale projects 'fixed' in particular places in the South, which 'reduce' emissions instead of Northern corporations with similarly immobile fossil fuel infrastructure.

Fixing projects in places that have made a smaller contribution to historical greenhouse gas emissions than the North is justified by the reductionist idea that it is immaterial where, how, and by whom a tonne of carbon is emitted (Lohmann, 2012). Carbon trading overcomes this tension by abstracting from the social dimensions of climate change using the singular measure of the quantity of carbon dioxide equivalent emitted or reduced from a socially constructed future scenario to calculate the production of carbon sinks. Abstract CERs spatially integrate the factories, mines, and farms registered as CDM projects with Northern governments that have Kyoto obligations and EU Emissions Trading System (ETS) installations. The geographical space between producers and consumers of carbon sink capacity also becomes a condition of production for the many carbon market service providers that facilitate CER commodity networks. The following section analyses and unpacks the socioecological relations engendered by the spatial fix through a case study of one project: the GFL HFC-23 destruction plant in Gujarat, India.

\section{Case study: HFC-23 destruction in Gujarat, India}

The GFL HFC-23 destruction project became the first CDM project when the CDM Executive Board registered it in 2005. Based in the Indian state of Gujarat, the factory's primary activity prior to involvement in the CDM was the production of the refrigerant gas HCFC-22 (GFL, 2003, page 14). The production of HCFC-22 results in the creation of the HFC-23 byproduct which has been designated with a global warming potential of 11700 by the Intergovernmental Panel on Climate Change, meaning 1 tonne of HFC-23 gas makes the equivalent contribution to global warming over 100 years as 11700 tons of carbon dioxide (IPCC, 2007, page 212). The company 'reduces' greenhouse gas emissions and therefore produces CER offsets by destroying HFC-23 with thermal oxidation technology (GFL, 2003, page 8). The high global warming potential of HFC-23 has enabled the GFL project to produce a disproportionately large quantity of CERs. As of 1 December 2014 the single project had been issued with 55.87 million CERs, representing 4\% of the total 1 billion-plus CERs issued to the 7579 
registered projects globally and $28 \%$ of CERs issued to India's 1535 registered projects (UNEP DTU, 2013).

Evidence of "gaming and abuse" of CDM rules by GFL's project developers and many of the other twenty-one registered HFC destruction projects, which had produced $35 \%$ of all CERs issued in the CDM by 1 December 2014, led the European Commission to ban all CERs from HFC-23 projects in the EU ETS from 2013 (Carbon Market Watch, 2010; European Commission, 2011; UNEP DTU, 2013). The GFL project has also come under prior media, activist, and academic scrutiny for its poor local record (Centre for Science and Environment, 2005a; Counter Review, 2013; Dabhi, 2009; Ghouri, 2009; Lohmann, 2006; Rosenthal, 2012; Rosenthal and Lehren, 2012; Sutter and Parreño, 2007). The large quantity of offsets produced by the GFL project and its widely documented local impacts provide significant empirical scope to examine the relationship between the accumulation opportunities along CER commodity networks and the socioecological impacts documented in this and many other offsetting projects (Böhm and Dabhi, 2009; Ghosh and Sahu, 2011; Lohmann, 2006).

The analysis in the case study is progressed using a range of primary and secondary qualitative and quantitative evidence. Documents from the UN and company reports show that the project has created highly profitable commodity networks for GFL and other CDM market actors. Publicly available EU ETS compliance data show that the project has also provided a successful political-economic fix for Northern capital. Fossil-fuel-intensive corporations have surrendered a considerable quantity of CERs produced by GFL under the EU ETS to cover excess carbon pollution and have used the credits for 'green' marketing purposes. However, our observations from field visits to the GFL site and surrounding villages and interviews with the people who live in them, as well as with GFL workers and activists from a Gujarati NGO, indicate the project is linked to the pollution of the environment and has damaged the health and livelihoods of the local community. ${ }^{(1)}$ The interviews were informal and nonrecorded due to the social and political volatility that surrounds the project but supported by media reports and government documents.

\section{Social and ecological dislocation}

The GFL plant is located in Ranjitnagar village, part of Ghoghamba Taluka in the Panchmahal District of the state of Gujarat. In total, 18273 people live in 3253 households in ten poor and rural villages within about $6 \mathrm{~km}$ of the project (Government of India, 2011a). ${ }^{(2)} 2011$ Indian Census information reveals that $75 \%$ of the working population in these villages are engaged in agriculture (Government of India, 2011a; 2011b). The majority of these are 'cultivators', meaning they farm their own privately or collectively owned land, rather than being employed as 'agricultural laborers'. The proportion of cultivators is higher than the rural average for India and indicates the importance of access to decent quality land for these communities' livelihoods (Government of India, 2011a; 2011b). There is also a very high proportion of people from the historically disadvantaged Scheduled Tribe groups at $56 \%$ compared with a national average of 11\% in rural areas (Government of India, 2011a; 2011b). The low literacy rate of $52 \%$ (the rural average for India is $68 \%$ ) is a useful proxy for the low human development in the villages, which have inadequate public education, health, and sanitation infrastructure (Government of India, 2011a; 2011b).

GFL has had a history of conflict with the local communities since the plant opened in 1989 (Rosenthal, 2012). The production of HCFC-22 is a prerequisite for the destruction of HFC-23 and therefore cannot be separated from the impacts of the CDM project.

(1) Dates of fieldwork were 22 March-15 April 2008 and 7-10 April 2010. Data collected were consistent across both stages.

(2) Virapura, Dudhapura, Rinchhiya, Rayan Mavuda, Chelavada, Nathkuva, Kankodakoi, Jitpura, Chadranagar. Interviews were conducted in the latter four and Ranjitnagar. 
Its production is a polluting and potentially toxic activity in its own right when its hazardous feed stocks (such as chloroform and sulfuric acid) and wastes are not treated and disposed of properly (GFL, 2003; US Environmental Protection Agency, 2000). HCFC-22 is also a potent greenhouse gas with a global warming potential of 1500 and an ozone-depleting substance listed for phase-out under the Montreal Protocol (IPCC, 2007, page 212). In 1996 community members were assisted by the Gujarati environmental organization Paryavaran Mitra in taking GFL to the Gujarat High Court over air and water pollution that they alleged was caused by the dumping of hazardous wastes. ${ }^{(3)}$ The court action was unsuccessful but local activists have continued to oppose the plant. For example, in 2005 an explosion in a tanker at the plant caused an oleum (sulfuric acid) leak, which local community members claim resulted in fifty hospital admissions (NDTV, 2006). In response, a protest at the GFL site resulted in eighty-four arrests (Ghouri, 2009; Rosenthal, 2012). Community members we interviewed informed us that twenty were detained for over a month and some were issued with court orders that exclude them from areas close to the GFL plant.

This social and ecological dislocation has been maintained and in some ways exacerbated by the addition of CDM project activities. GFL destroys HFC-23 by capturing rather than venting the gas and incinerating it at high temperatures in a thermal oxidation chamber (GFL, 2003, page 8). The goal of the process is to convert HFC-23 into carbon dioxide and water. However, the GFL project design document (PDD) lists numerous other substances that are used in, or are byproducts, of the incineration that are potentially hazardous to humans and/or the environment (US Department of Labor, 2014). The PDD states the thermal incineration process creates hydrochloric acid and hydrogen fluoride, results in the release of carbon monoxide, sulfur dioxide, and nitrous oxide, and uses caustic soda (sodium hydroxide) and hydrated lime (calcium hydroxide) (GFL, 2003, page 9). It also produces greenhouse gas emissions through the combustion of liquefied petroleum gas at the site and the purchase of fossil-fuel-powered electricity from the grid (GFL, 2003, page 9). The PDD states these chemicals are recycled, recovered, or treated through venting, scrubbing, and cooling (GFL, 2003, pages 19-21). However, activists we interviewed from Paryavaran Mitra claim that GFL's history of discharging chemicals into the air, water, and land around the plant has continued with the CDM project activities.

Results of tests of groundwater in the local area by the Department of Drinking Water Supply are consistent with pollution created by the production of HCFC-22 and the destruction of HFC-23. Wells in Ranjitnagar and five of the nine villages surrounding the GFL plant recorded fluoride concentrations classified as "above permissible levels" at up to $7.97 \mathrm{mg} / \mathrm{l}$ in tests carried out between April 2009 and April 2011 (Government of India, 2011c). ${ }^{(4)}$ At low levels fluoride can have positive impacts for dental health, but drinking water containing over $3 \mathrm{mg} / \mathrm{l}$ of fluoride can cause skeletal fluorosis (World Health Organization, 2004, page 5). The villages of Ranjitnagar and Nathvuka also recorded "above permissible levels" of chloride at up to $1344 \mathrm{mg} / 1$ and $4424 \mathrm{mg} / \mathrm{l}$ in tests carried out on 9 March 2011 and 6 May 2009, respectively (Government of India, 2011c). Chloride toxicity can occur in crops when chloride concentrations exceed tolerance levels, causing burning and drying of leaves (Food and Agriculture Organization, 1985). The presence of chloride in water is not harmful to human health, but is an indicator for industrial waste (World Health Organization, 2003, page 2).

(3) Andarsingh Mangalsingh Parmar and Udaisingh Mohanbhai Baria vs Gujarat Fluorochemicals Limited, State of Gujarat, The Chairman Gujarat Pollution Control Board, The Chairman Gujarat Industrial Development Corporation and The Chairman Gujarat Electricity Board (Special Civil Application No. 5280 of 1995).

${ }^{(4)}$ Water samples from Jitpura, Virapura, Dudhapura, Rinchhiya, and Rayan Mavuda. 
Problems with human health and agricultural production in the villages surrounding the project are consistent with the impacts of the pollutants present in the water supply that are involved in GFL's original and CDM activities: oily films on the water and white crusts on the soil that can be observed in the vicinity of the project (see also Ghouri, 2009). As a result of this pollution, local farmers we interviewed claimed to have suffered from a reduction in the productivity, quality, and absolute yields of corn, cotton, and rice in recent years. They said mango and papaya had also become particularly prone to rapid decay (see also NDTV, 2006). Local community members told us that they were suffering from endemic eye and skin conditions such as skin pigmentation disorders, rashes and eye irritation, joint pains, and decreased fertility (see also Rosenthal, 2012). People we interviewed strongly asserted that pollution released from the GFL plant was to blame for these problems.

The negative impacts of the GFL project on the local community have not been offset by the benefits promised by the project developers in the PDD, despite some local community members reporting that local air quality had improved following the reduction in HFC-23 venting. The PDD promised employment for thirty to forty mostly unskilled workers in the operation of the HFC-23 destruction plant (GFL, 2003, page 57). However, local community members and GFL workers told us that many of the additional jobs had bypassed the local community in favor of lower paid workers from the northern states of Uttar Pradesh and Bihar. The company's promise to spend 70 million Indian rupees (US \$1.13 million) on 'sustainable development' over the course of the project has also not materialized (GFL, 2003, page 83). ${ }^{(5)}$ Local farmers told us that GFL had been supplying them with two bags of urea and one bag of diammonium phosphate fertilizer each monsoon. However, it requires continually increasing quantities and has been prone to steep price rises, exposing farmers to a potentially unsustainable situation once the GFL project ceases (Mukherjee, 2011). Community members told us that, rather than engaging with them on community development initiatives, GFL has employed a strategy of offering money to individual protest leaders in return for silence. Almost halfway through the ten-year project crediting period we found no evidence for any of the other promises made in the PDD, such as improved sanitation services, being fulfilled by the company (GFL, 2003, page 83).

\section{Protecting fossil fuel industries and promoting accumulation}

The economic benefits from the GFL project for actors other than the local community can be documented throughout the various CER commodity networks engendered by destruction of HFC-23. GFL, the project developer and owner of the plant, has been the primary financial beneficiary of the project. Revenue from the sale of CERs following CDM registration has significantly increased the profitability of GFL. ${ }^{(6)}$ Multiple annual reports following CDM registration state "the sale of carbon credits to European buyers has added a healthy revenue stream to your company's operating results" (eg, GFL, 2006, page 6). GFL increased its total profit by $150 \%$ in 2006/07, its first year of CDM trading, by selling 3.9 billion Indian rupees (US \$62.97 million) worth of CERs. Revenue from CER sales went from zero prior to CDM project status to an average of $46 \%$ of total sales between 2006/07 and 2012/13, which more than supplemented revenue from the production of refrigerant gases and demonstrated the effective integration of CER and other forms of commodity production (see table 1). Figures in the company's annual reports, reproduced in table 1 and figure 1 , show that revenue remained steady or increased in the years until 2010/11 when global carbon prices dropped. Perversely, revenue and profits increased in 2011/12 following the decision by the European

${ }^{(5)}$ All exchange rates from http://www.xe.com and accurate 1 December 2014, with US $\$ 1=$ Rs. $61.93=€ 80.08$.

${ }^{(6)}$ A small proportion of GFL revenue (from the issuance and sale of 100000 CERs) derives from two other wind farm CDM projects operated by GFL in the states of Rajasthan and Maharashtra. 
Table 1. Nominal Gujarat Fluorochemicals Limited financial results, 2002-13 (GFL, 2014).

\begin{tabular}{lcllc}
\hline $\begin{array}{l}\text { Financial } \\
\text { year }\end{array}$ & $\begin{array}{l}\text { Revenue from CER } \\
\text { sales (US \$ million) }\end{array}$ & $\begin{array}{l}\text { Total sales income } \\
\text { (US \$ million) }\end{array}$ & $\begin{array}{l}\text { CER as \% of total } \\
\text { sales income }\end{array}$ & $\begin{array}{l}\text { Profit after taxation } \\
\text { (US \$ million) }\end{array}$ \\
\hline $2002 / 03$ & 0.0 & 22.3 & 0.0 & 6.2 \\
$2003 / 04$ & 0.0 & 25.3 & 0.0 & 9.5 \\
$2004 / 05$ & 0.0 & 28.7 & 0.0 & 8.1 \\
$2005 / 06$ & 0.0 & 30.3 & 0.0 & 17.7 \\
$2006 / 07$ & 63.0 & 94.0 & 67.0 & 44.5 \\
$2007 / 08$ & 73.3 & 119.9 & 61.1 & 58.9 \\
$2008 / 09$ & 101.6 & 173.0 & 58.7 & 62.7 \\
$2009 / 10$ & 76.4 & 162.5 & 47.0 & 61.5 \\
$2010 / 11$ & 32.7 & 164.3 & 19.9 & 47.9 \\
$2011 / 12$ & 141.5 & 343.6 & 41.2 & 138.9 \\
$2012 / 13$ & 71.3 & 270.8 & 26.3 & 73.4 \\
$2013 / 14$ & 0.1 & 197.0 & 0.05 & 13.7
\end{tabular}

Note. CER-Certified Emission Reduction.

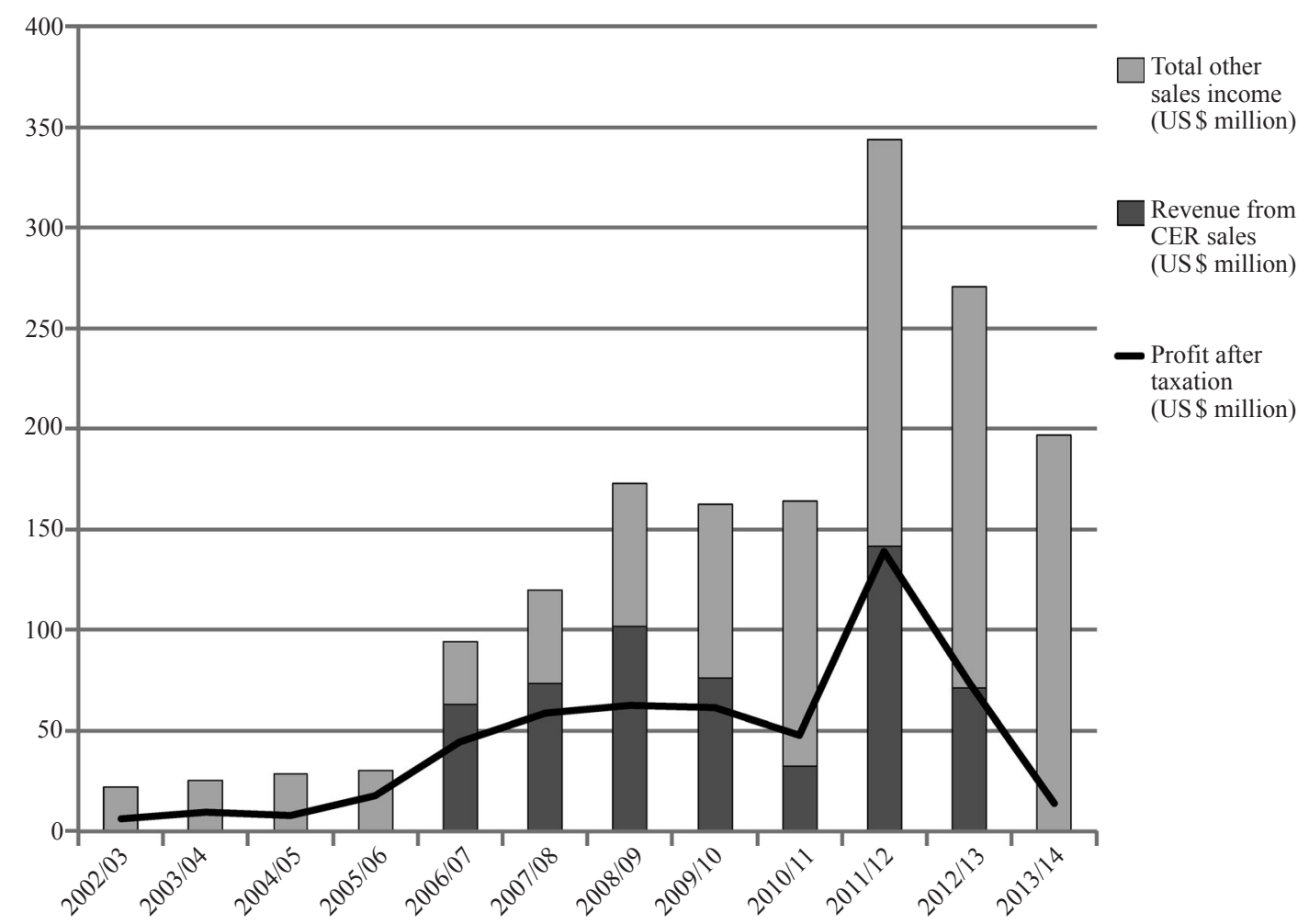

Figure 1. Nominal Gujarat Fluorochemicals Limited financial results, 2002-13 (GFL, 2014).

Commission to ban HFC-23 CERs in the EU ETS from 2013, corresponding with a general trend of European companies rushing to surrender CERs from industrial gas projects while they still could (BusinessGreen, 2012). However, the decision led to a fall in carbon credit revenue to just $\$ 0.1$ million in 2013/14.

The profitability of GFL's CDM operations can be attributed to low initial capital and operating costs compared with average 2012 CER futures prices of $€ 10.90$ (US\$13.61) during the second phase of the EU ETS between 2008 and 2012 (Intercontinental Exchange, 2014). The total investment in thermal oxidation technology was estimated at 
only 130 million Indian rupees (US $\$ 2.1$ million) and the process of destroying HFC-23 is estimated at costing only US $\$ 0.50$ per tonne of carbon dioxide-equivalent (Centre for Science and Environment, 2005b; Schwank, 2004). GFL has reinvested its profits from the sale of CERs to expand its chemicals businesses through the commissioning and construction of new caustic soda/chlorine, chloromethane, and polytetrafluoroethylene (PTFE, commonly known as Teflon) plants and internal electricity generation capacity as well as to other industries including renewable energy and cinemas through its subsidiaries Inox Wind and Inox Leisure. It was reported to have leveraged CER revenues to finance a capital expenditure program in these areas that would increase its asset base by five-fold (CRISIL, 2013; Money Times 2014). Figure 1 shows that, while these investments contributed to revenues from GFL's chemicals business remaining relatively strong following the end of the CER business, profit levels were not sustained.

In addition to GFL, there are a number of project participants, primarily based in the Global North, that have gained financially from their direct involvement in the GFL project. The technology used to destroy HFC-23 was supplied by UK company Ineos Fluor Limited, which received a portion of the CERs produced in return (GFL, 2003, page 11). Between 2008 and 2012 three installations based in the UK, Germany, and Norway, ${ }^{(7)}$ owned by chemicals manufacturer Ineos Group, which owned Ineos Fluor until 2010, surrendered 45249 CERs produced by GFL for compliance purposes under the EU ETS (European Commission, 2013). ${ }^{(8)}$ Sumitomo Corporation received another portion of GFL CERs in return for maintenance carried out by Daikin Industries on the plant (GFL, 2003, page 12). The Japanese company justified its role in GFL and other CDM projects as being designed to meet Japan's Kyoto Protocol targets and has used GFL CERs to market air conditioner filters as "carbon neutral" (Sumitomo Corporation, 2005, page 29; 2010). Three private consultancy firms have provided fee-based services to the project including the Mumbai office of PricewaterhouseCoopers, which prepared the PDD; SGS United Kingdom, which validated the project; and DNV Climate Services Denmark, which verified the emission reductions (GFL, 2003, page 1; UNEP DTU, 2014). The Government of India approved the project as meeting its sustainable development guidelines and has gained additional taxation revenue from GFL by subjecting CER sales to a $30 \%$ corporate tax rate (BS Reporter, 2010). Dutch banking corporation Rabobank has acted as a mediator between GFL and the Government of the Netherlands in the purchase of CERs in line with the latter's Kyoto obligations (GFL, 2003, page 12).

Beyond the immediate project participants the CERs produced by the GFL have benefited other financial institutions that trade in secondary carbon markets (figure 2). For example, the London office of carbon broker Natsource Tullett brokered a deal for Ineos Fluor to sell two million CERs from GFL to an 'undisclosed' European corporation over six years from 2006 (Ineos, 2004). Carbon investor Noble Carbon Credits - a subsidiary of global energy, agriculture, and industrial conglomerate Noble Group - purchased GFL CERs to form part of its claimed 15\% market share in CERs (Kalesh, 2006; Noble Group, 2013; UNEP DTU, 2014). Carbon traders like Noble Carbon Credits and Natsource Tullett can profit from these over-the-counter trades by taking advantage of the changing price differentials between EU ETS allowances and CERs. CERs are also traded on exchanges like European Climate Exchange and are used to create financial instruments such as futures, options, and other derivatives (Ellerman et al, 2010, pages 139-146). As a large producer of CERs globally, the GFL project has made a significant contribution to the formation and operation of these financial markets.

(7) Installation names: INEOS Norge AS (Norway), Ammoniakanlage-Hilfskessel O6 (Germany), and Grangemouth Chemicals (UK).

${ }^{(8)}$ All installation ownership data from Carbon Market Data (2014) and defined as a greater than $50 \%+1$ stake. 


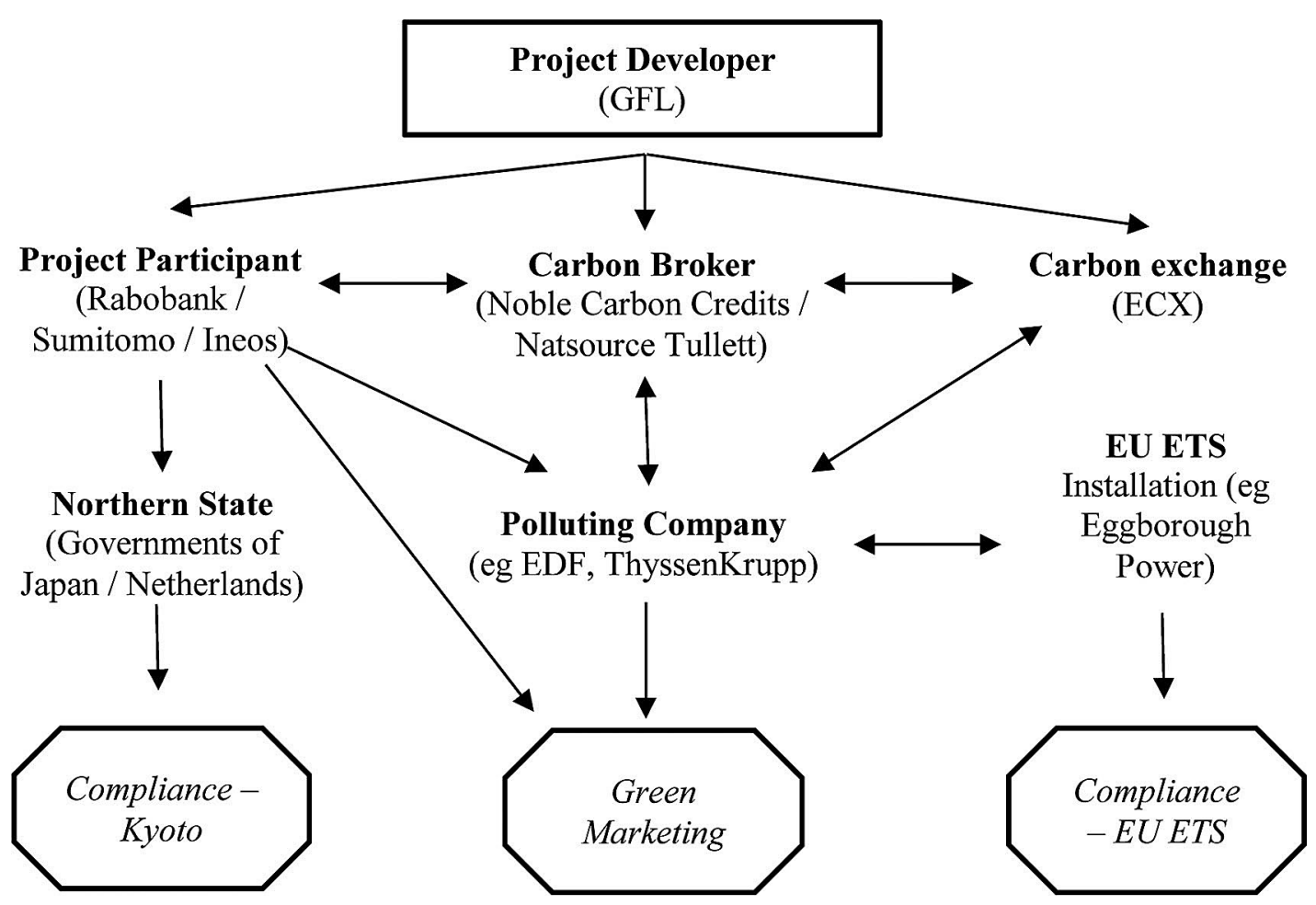

Figure 2. Gujarat Fluorochemicals Limited (GFL) Certified Emission Reductions commodity network. Note. ECX-European Climate Exchange; EDF—Électricité de France; EU ETS-EU Emissions Trading System.

Many large energy companies have also set up their own carbon trading offices. For example, Électricité de France (EDF), the state-owned corporatized French energy giant, set up a $€ 290$ million carbon fund through EDF Trading, which develops projects and trades CERs with EDF subsidiaries and third parties (EDF Trading, 2013). Installations owned by EDF surrendered 462476 CERs produced by GFL between 2008 and 2012 with almost half by its UK energy utilities (European Commission, 2013). EDF has also used the trading and purchase of CERs to cultivate a 'green' marketing image for competitive advantage in the UK energy market. EDF Group's (2009, page 72) Activity and Sustainable Development Report states that the purchase of CERs from India forms part of its "commitment to energy eco-efficiency" which aligns with EDF Energy's (UK) green marketing campaign that saw it sponsor the 2012 London Olympics as "official sustainability partner" (EDF Energy, 2013).

Most importantly, the primary use value of CERs for the fossil fuel industry is their compliance value under the EU ETS. Between 2008 and 2012, 1120 installations (about 8\% of total EU ETS installations) surrendered 47.02 million GFL CERs (European Commission, 2013). This accounted for $7 \%$ of the total 675.39 million CERs surrendered by EU ETS installations from all CDM projects in this period (European Commission, 2013). Therefore, the CDM, and the GFL project in particular, has enabled Northern companies to emit millions of tonnes more carbon dioxide than they otherwise would have been able to. Surrendered GFL credits have been concentrated in a few large installations and companies, with the top-ten installations surrendering 11.64 million CERs (European Commission, 2013). They include coal-fired power plants, such as the Eggborough Power Station in East Yorkshire, UK, which on average exceeded its allocated allowances by $41.24 \%$ in the second phase of the EU ETS and surrendered 794218 GFL CERs to help meet the shortfall (Carbon Market Data, 2014; European Commission, 2013). 
However, not all CERs surrendered for compliance in the EU ETS were necessary for installations to emit overallocated caps. Integriertes Hüttenwerk Duisburg, a steel manufacturing installation in Duisburg, Germany, that is part-owned by ThyssenKrupp and which also manages their trading account, surrendered the largest quantity of GFL credits at 3.12 million CERs (European Commission, 2013). At both the installation and company level, free allocation exceeded verified emissions, leading to a substantial surplus of European permits (Carbon Market Data, 2014; European Commission, 2014). The option of surrendering CERs for Integriertes Hüttenwerk Duisburg's excess emissions would have allowed ThyssenKrupp to bank its surplus European permits or take advantage of their higher price than CERs by freeing them up to sell.

\section{Discussion and conclusions}

Through the GFL case study the CDM can be understood as a spatial fix in a variety of ways. First, the CDM allows Northern states, such as Japan and the Netherlands, to meet their Kyoto targets by exporting their emission reduction efforts to the South, minimizing the need to fundamentally restructure their own fossil-fuel-dependent economies. Second, purchasing CERs enables publicly and privately owned companies with emissions reduction requirements under the EU ETS, like Ineos and Eggborough Power, to meet their targets without paying higher costs associated with reducing pollution from their own production activities and thereby maintaining their own rates of accumulation. In both cases states have secured ongoing access for these actors to material carbon sinks, and therefore fossil fuels, as conditions of production.

Third, the availability of cheap CERs through the CDM allows polluting companies in the North, including Sumitomo and EDF, to market themselves in 'green' ways, quite separate from their direct social relations with nature. Fourth, the economic activity generated by the production of CERs provides project participants and other CDM actors without emission reduction requirements, including project developers such as GFL and carbon brokers and consultants like Natsource Tullet, with a new source of profits derived through the climate crisis. Both are examples of the economic benefits of securing carbon sinks as conditions of production in abstract form through their commodification.

Each political-economic fix is inextricably linked to materially fixed CDM projects by the mechanism of carbon trading, which integrates internal and external spaces of Global North and South fixed at UN climate negotiations. The carbon market enables the costs of responding to the climate crisis to be displaced from (also fixed) polluting industries in the North to communities in the South. The negative impacts of displacement at the local level are caused by a conflict between the accumulation imperatives driving the political economic fix and the needs of the communities and environments surrounding fixed projects in the South. Substituting emission reductions in the North for the destruction of HFC-23 necessarily appropriates land, water, and ecological systems at the local level. Indeed, the production of carbon credits in this way both depends on, and financially supports, polluting HCFC-22 production. However, the conditions of production for CDM project developers are also "conditions of human life" for local communities that require and manage healthy ecosystems, clean water, and access to land to sustain their livelihoods (O'Connor, 1998, page 155).

The conditions of life around CDM projects are not valued through CDM verification processes or EU ETS and Kyoto compliance requirements. Indeed, the displacement of the costs of CER production to these local conditions increases the profitability of participation in the CDM market for project developers and Northern polluters. All CDM projects, whether coal-bed methane or hydropower, are materially dependent on local conditions of production and therefore have the potential to negatively impact local communities and ecosystems 
in the course of maximizing profits. Space is therefore fixed and global and local scales reconfigured in the interests of the four political-economic fixes outlined above rather than the interests of communities affected by CDM projects.

Voluntary schemes, such as the CDM Gold Standard, have attempted to value the conditions of life around CDM projects and have been profitable for a limited number of CDM market actors (Dhanda and Hartman, 2011). For example, the consultancy firms which verify the additional social and environmental standards benefit from increased business, project developers receive a premium price for their offsets, and the polluting companies that purchase them gain additional marketing benefits beyond simple compliance (Paterson, 2010, page 361). But these profits are dependent on differentiation from a main CDM market with less stringent regulations. Enforcement of such standards for all projects would act as drag on the overall accumulation rationale of the CDM by raising costs for all project developers and/or polluters while eliminating the financial benefits of ecolabelled offsets as they are currently designed. Climate policy is riddled with contradictory interests over fundamental issues such as emissions caps. However, the accumulation imperatives for both old fossil-fuel-intensive and new for-profit CDM market actors line up with the relatively cheap production of CERs, which is supported by weak social and environmental regulation of projects at the local level (Paton and Bryant, 2012). For example, in the GFL case a greater distribution of CER revenue to local communities or enhanced pollution controls would have either reduced the profit margins for GFL or, if passed on, increased compliance costs for the polluting industries in the North.

This suggests there are significant political-economic limitations to the potential to reform the sustainable development governance of the CDM without challenging the rationale of the instrument itself (see Paulsson, 2009; Sutter and Parreño, 2007). Nonetheless, the campaign directed towards the European Commission to ban HFC-23 offsets from the CDM was a major success (Carbon Market Watch, 2014). The ban means CERs produced by GFL will no longer provide a 'fix' for European companies, and GFL (2012, page 12) has acknowledged its profits from the CDM will dry up. Nevertheless, the analysis of the commodity networks presented in this paper remains relevant for other project types that are still producing offsets because eligible CERs are homogenous commodities when traded in carbon markets. Hence, we expect similar dynamics and patterns can be observed in other CDM and voluntary offset projects (Lohmann, 2012).

However, Harvey's (1982, page 442) contention that "there is, in short, no 'spatial fix' that can contain the contradictions of capitalism in the long run" appears to be already playing out due to the all-too-visible contradictions within the accumulation rationale of the CDM. CER prices have hovered around and below $€ 1$ since 2013 due to the large surplus of European and offset permits in the EU ETS, which is projected to reach 3.1 billion credits by 2020 as a result of overallocation, economic crisis, and the flooding of CERs into the market relative to demand (Morris, 2012). The reluctance of EU institutions to go beyond minor reforms to increase the demand for and the price of CERs by drastically decreasing emissions caps and permanently withdrawing a substantial quantity of EU permits has erased many profitmaking opportunities in the CDM market (Lang, 2014). Financial institutions in the City of London have been radically scaling back their carbon trading operations and proposals for new CDM projects from project developers have dried up, demonstrating that the current configuration of the spatial fix is not working for these actors (Pickard and Makan, 2013; UNEP DTU, 2014).

The overproduction of CERs in this context is a symptom of states prioritizing parts of the political-economic fix aimed at securing cheap emission reductions for polluting companies in the North. The political priority given to fossil-fuel-dependent capital has been at the expense of the economic interests of carbon trading industries that generally benefit 
from higher carbon prices, notwithstanding the potential for financial actors to profit from market volatility at any price. This suggests that there may also be political-economic limits for states in the implementation of carbon trading as an accumulation strategy for both fossil fuel and 'green' industries.

Acknowledgements. Thanks to Mahesh Pandya and his team at Paryavaran Mitra, Nayan Patel, and Noor Rathod from Yuva Shakti, Neeta Hardikar from Anandi, Robert David, and all the local villagers and others who were interviewed in the course of the research. Thanks also to Stuart Rosewarne and Joy Paton for their advice at across multiple drafts, Esteve Corbera and Adrian Martin for putting together this special issue, and Environment and Planning A's editors, staff, and excellent reviewers who provided invaluable criticisms and suggestions.

\section{References}

Bachram H, 2004, "Climate fraud and carbon colonialism: the new trade in greenhouse gases" Capitalism Nature Socialism 15 5-20

Bailey I, Wilson, G A, 2009, "Theorising transitional pathways in response to climate change: technocentrism, ecocentrism, and the carbon economy" Environment and Planning A $\mathbf{4 1}$ 2324-2341

Betsill M, 2002, "Environmental NGOs meet the sovereign state: the Kyoto Protocol negotiations on global climate change" Colorado Journal of International Environmental Law and Policy 13 49-64

Böhm S, Dabhi S, 2009 Upsetting the Offset: The Political Economy of Carbon Markets (MayFly Books, London)

Böhm S, Misoczky M C, Moog S, 2012, "Greening capitalism? A Marxist critique of carbon markets" Organization Studies 33 1617-1638

Bond P, 2007, "Privatization of the air turns lethal: 'pay to pollute' principle kills South African activist Sajida Khan" Capitalism Nature Socialism 18(4) 6-37

Bond P, 2012, "Emissions trading, new enclosures and eco-social contestation" Antipode 44 684-701

Boyd E, 2009, "Governing the Clean Development Mechanism: global rhetoric versus local realities in carbon sequestration projects" Environment and Planning A 41 2380-2395

Brenner N, 1998, "Between fixity and motion: accumulation, territorial organization and the historical geography of spatial scales" Environment and Planning D: Society and Space $\mathbf{1 6}$ 459-482

BS Reporter, 2010, "Carbon credits to be taxable under corporate income" Business Standard India, http://www.business-standard.com/article/economy-policy/carbon-credits-to-be-taxable-undercorporate-income-110090100102_1.html

Bumpus A G, 2011, "The matter of carbon: understanding the materiality of tCO2e in carbon offsets" Antipode 43 612-638

Bumpus A G, Liverman D M, 2008, "Accumulation by decarbonization and the governance of carbon offsets" Economic Geography 84 127-155

BusinessGreen, 2012, "Companies rush to surrender industrial gas credits before ban", http://www.businessgreen.com/bg/news/2178555/companies-rush-surrender-industrial-gas-creditsban

Carbon Market Data, 2014, "EU ETS Companies Database", https://www.carbonmarketdata.com

Carbon Market Watch, 2010, "UN under pressure to halt gaming and abuse of CDM", http://carbonmarketwatch.org/un-under-pressure-to-halt-gaming-and-abuse-of-cdm/

Carbon Market Watch, 2014, "Industrial gas CDM projects (HFC-23 \& N2O) archive - Carbon Market Watch", http://carbonmarketwatch.org/category/additionality-and-baselines/industrial-gases/

Castree N, 2002, "False antitheses? Marxism, nature and actor-networks" Antipode 34 111-146

Centre for Science and Environment, 2005a, "Newest biggest deal" Down to Earth 15 November, http://www.downtoearth.org.in/node/10354

Centre for Science and Environment, 2005b, "Making the cheap development mechanism clean: how?", http://old.cseindia.org/programme/geg/pdf/CDM-presentation.pdf

Corbera E, Brown, K, 2010, "Offsetting benefits? Analyzing access to forest carbon" Environment and Planning A 42 1739-1761 
Counter Review, 2013, "Paryavaran Mitra finds out the hard way how clean development projects have turned into a means spin money", http://counterview.org/2013/06/29/paryavaran-mitra-finds-the-hard-way-how-clean-developmentprojects-have-turned-into-a-means-spin-money/

CRISIL, 2013, "CRISIL reaffirms A1+ rating on Gujarat Fluorochemicals' CP, Cogencis" MoneyWire 4 July

Dabhi S, 2009, "Where is climate justice in India's first CDM project?", in Upsetting the Offset: The Political Economy of Carbon Markets Eds S Böhm, S Dabhi (MayFly Books, London) pp 138147

Dhanda K K, Hartman L P, 2011, "The ethics of carbon neutrality: a critical examination of voluntary carbon offset providers" Journal of Business Ethics 100(1) 119-149

EDF Energy, 2013, "Our partnership with London 2012", http://www.edfenergy.com/about-us/sponsorship/london-2012.shtml

EDF Group, 2009, "Activity and sustainable development report 2009", http://www.edf.com/html/RA2009/uk/pdf/EDF_RA09_full_va.pdf

EDF Trading, 2013, "Commodities - environmental products", http://www.edftrading.com/Commodities/Environmental-products

Ellerman A D, Convery F, De Perthuis C, 2010 Pricing Carbon: The European Union Emissions Trading Scheme (Cambridge University Press, Cambridge)

European Commission

2011, "Commission adopts ban on the use of industrial gas credits-European Commission", http://ec.europa.eu/clima/news/articles/news_2011060801_en.htm

2013, "CERs and ERUs surrendered under the EU ETS", http://ec.europa.eu/clima/policies/ets/registry/docs/compliance_2012_ic_en.xls

2014, "European Union Transaction Log", http://ec.europa.eu/environment/ets/

European Environment Agency, 2012, "EUA future prices 2005-2011", http://www.eea.europa.eu/data-and-maps/figures/eua-future-prices-200520132011

Food and Agriculture Organization, 1985, "Water quality for agriculture", http://www.fao.org/docrep/003/t0234e/t0234e05.htm

GFL, Gujarat Fluorochemicals Limited

2003, "CDM: Project for GHG emission reduction by thermal oxidation of HFC 23 in Gujarat, India", http://cdm.unfccc.int/Projects/DB/SGS-UKL1092749325.58

2006, "19th annual report 2005-06", http://www.gfl.co.in/Annual\%20Reports/GFL\%20Annual\%20Report\%202005-06.pdf

2012, "25th annual report 2011-12", http://www.gfl.co.in/Annual\%20Reports/GFL\%20Annual\%20Report\%202011-12.pdf

2014, "Financial Results", http://www.gfl.co.in/Financial_\%20Results.htm

Ghosh S, Sahu S K, 2011 The Indian Clean Development Mechanism: Subsidizing and Legitimizing Corporate Pollution, an Overview of CDM in India with Case Studies from Various Sectors DISHA, Kolkata

Ghouri N, 2009, "The great carbon credit con: why are we paying the Third World to poison its environment?" Daily Mail, http://www.dailymail.co.uk/home/moslive/article-1188937/The-great-carbon-credit-eco-companiescausing-pollution.html

Government of India

2011a, "Primary census abstract (PCA) data", http://www.censusindia.gov.in/pca/final_pca.aspx

2011b, "Census of India. Primary Census Abstract. Figures at a Glance.", Ministry of Home Affairs, http://www.censusindia.gov.in/2011 census/PCA/PCA_Highlights/pca_highlights_file/ India/5Figures_at_glance.pdf

2011c, "Department of Drinking Water Supply", http://indiawater.gov.in

Grubb M, Vrolijk C, Brack D, 1999 The Kyoto Protocol: A Guide and Assessment (Earthscan, London)

Harvey D, 1982 The Limits to Capital (Blackwell, Oxford)

Harvey D, 1995, "Globalization in question" Rethinking Marxism 8(4) 1-17

Harvey D, 1996 Justice, Nature and the Geography of Difference (Blackwell, Cambridge, MA) 
Harvey D, 2001, "Globalization and the spatial fix" Geographische Revue $223-30$

Harvey D, 2003 The New Imperialism (Oxford University Press, Oxford)

Huber M T, 2009, "Energizing historical materialism: fossil fuels, space and the capitalist mode of production" Geoforum 40 105-115

Ineos, 2004, "INEOS Fluor confirm forward sale of two million tonnes of Certified Emission

Reductions",

http://www.ineos.com/News/ /INEOS-Fluor-confirm-forward-sale-of-two-million-tonnes-of-Certified-

Emission-Reductions/?items $=10$ \&businesses $=4$ \&year $=$ \&page $=13$

InterContinental Exchange, 2014, "ICE Futures Europe", https://www.theice.com/futures-europe

IPCC, 2007 Climate Change 2007: The Physical Science Basis Intergovernmental Panel on Climate Change (Cambridge University Press, Cambridge)

Kalesh B, 2006, "Gujarat Fluro sets record on carbon credit sale" The Times Of India, http://articles.timesofindia.indiatimes.com/2006-08-09/india-business/27826809_1_gfl-carbondioxide-carbon-emissions

Lang C, 2014, "Global carbon markets have shrunk in value by 60\% since 2011" REDD Monitor, http://www.redd-monitor.org/2014/01/09/global-carbon-markets-have-shrunk-in-value-by-60since-2011/

Lansing D M, 2010, "Carbon's calculatory spaces: the emergence of carbon offsets in Costa Rica" Environment and Planning D: Society and Space 28 710-725

Levy D, Egan D, 1998, "Capital contests: national and transnational channels of corporate influence on the climate change negotiations" Politics and Society 26 337-362

Lohmann L, 2006 Carbon Trading: A Critical Conversation on Climate Change, Privatization and Power (Dag Hammarskjöld Foundation, Uppsala)

Lohmann L, 2010, "Uncertainty markets and carbon markets: variations on Polanyian themes" New Political Economy 15 225-254

Lohmann L, 2012, "Financialization, commodification and carbon: the contradictions of neoliberal climate policy" Socialist Register $\mathbf{4 8}$

Malm A, 2013, "The origins of fossil capital: from water to steam in the British cotton industry" Historical Materialism 21(1) 15-68

Matthews K, Paterson M, 2005, "Boom or bust? The economic engine behind the drive for climate change policy" Global Change, Peace and Security 17 59-75

Money Times 2014, "Gujarat Fluorochemicals", Time Communications (India) Limited, 14 July

Morris D, 2012, "Losing the lead? Europe's flagging carbon market”, Sandbag Climate Campaign, London

Mukherjee B, 2011, "Fertilizer shortage: farmers block NH, 8 arrested" The Times Of India, http://articles.timesofindia.indiatimes.com/2011-10-25/chandigarh/30319635_1_fertilizer-dap-farmers

NDTV, 2006, "Villagers up in arms against GFCL plant", http://www.ndtv.com/video/player/news/villagers-up-in-arms-against-gfcl-plant/3292

Noble Group, 2013, “What is Noble doing?", http://www.thisisnoble.com/index.php?option=com_ content\&view=article\&id=519\&ltemid=458\&lang=en

O'Connor, J, 1998 Natural Causes: Essays in Ecological Marxism (The Guilford Press, New York)

Paterson M, 2010, "Legitimation and accumulation in climate change governance" New Political Economy 15 345-368

Paton J, Bryant G, 2012, "Valuing pollution: problems of price in the commodification of nature" The Economic and Labour Relations Review: ELRR 23(1) 87-106

Paulsson E, 2009, "A review of the CDM literature: from fine-tuning to critical scrutiny?" International Environmental Agreements: Politics, Law and Economics 9 63-80

Pickard J, Makan,A, 2013, "London banks quit carbon trading" Financial Times, http://www.ft.com/cms/s/0/cbb749ba-506b-11e3-9f0d-00144feabdc0.html\#axzz2ovRYEoeg

Rosenthal E, 2012, "Indian village at odds with Gujarat fluorochemicals plant" The New York Times, http://www.nytimes.com/2012/08/09/world/asia/indian-village-at-odds-with-gujarat-fluorochemicalsplant.html 
Rosenthal E, Lehren A W, 2012, "Incentive to slow climate change drives output of harmful gases" The New York Times, http://www.nytimes.com/2012/08/09/world/asia/incentive-to-slow-climate-change-drives-output-ofharmful-gases.html

Rosewarne S, 1997, "Marxism, the second contradiction, and socialist ecology" Capitalism Nature Socialism $899-120$

Schwank O, 2004, "Concerns about CDM projects based on decomposition of HFC-23 emissions from 22 HCFC production sites", http://cdm.unfccc.int/public_inputs/inputam0001/Comment_AM0001_Schwank_081004.pdf

Smith N, 2006, "Nature as accumulation strategy", in Socialist Register 2007 Eds L Panitch, C Leys (Merlin Press, London) pp 19-41

Smith N, 2008 Uneven Development: Nature, Capital, and the Production of Space 3rd edition (Verso, London)

Stern N, 2007 The Economics of Climate Change: The Stern Review (Cambridge University Press, Cambridge)

Sumitomo Corporation, 2005, "Social and environmental report 2005", http://www.sumitomocorp.co.jp/english/society/doc/env2005e.pdf

Sumitomo Corporation, 2010, "Sumitomo Shoji Machinex Co., Ltd. launches the industry's first carbon neutral air conditioner filter reuse service", http://www.sumitomocorp.co.jp/english/topics/2010/20100720_213720.html

Sutter C, Parreño J C, 2007, "Does the current Clean Development Mechanism (CDM) deliver its sustainable development claim? An analysis of officially registered CDM projects" Climatic Change 84(1) 75-90

UNEP DTU, 2014, “CDM Pipeline overview December 2014”, http://www.cdmpipeline.org/

UNFCCC, 1997, "The Kyoto Protocol", United Nations Framework Convention on Climate Change

US Department of Labor, 2014, "Toxic Industrial Chemicals (TICs) Guide", https://www.osha.gov/SLTC/emergencypreparedness/guides/chemical.html

US Environmental Protection Agency, 2000, "Chloroform = hazard summary", http://www.epa.gov/ttn/atw/hlthef/chlorofo.html

Vlachou A, Konstantinidis C, 2010, "Climate change: the political economy of Kyoto flexible mechanisms" Review of Radical Political Economics 42(1) 32-49

World Health Organization, 2003, "Chloride in drinking-water", http://www.who.int/water_sanitation_health/dwq/chloride.pdf

World Health Organization, 2004, "Fluoride in drinking-water", http://www.who.int/water_sanitation_health/publications/fluoride_drinking_water/en/

Yamane A, 2009, "Climate change and hazardscape of Sri Lanka" Environment and Planning A $412396-2416$ 